\title{
Dual Regulation of TRPV1 by Phosphoinositides
}

\author{
Viktor Lukacs, ${ }^{1 \star}$ Baskaran Thyagarajan, ${ }^{1 \star}$ Peter Varnai, ${ }^{2}$ Andras Balla, ${ }^{2}$ Tamas Balla, ${ }^{2}$ and Tibor Rohacs ${ }^{1}$ \\ ${ }^{1}$ Department of Pharmacology and Physiology, University of Medicine and Dentistry of New Jersey-New Jersey Medical School, Newark, New Jersey 07103, \\ and ${ }^{2}$ Endocrinology and Reproduction Research Branch, National Institute of Child Health and Human Development, National Institutes of Health, \\ Bethesda, Maryland 20892
}

The membrane phospholipid phosphatidylinositol 4,5-bisphosphate $\left[\operatorname{Ptd} \operatorname{Ins}(4,5) \mathrm{P}_{2}\right.$ or $\left.\mathrm{PIP}_{2}\right]$ regulates many ion channels. There are conflicting reports on the effect of PtdIns $(4,5) \mathrm{P}_{2}$ on transient receptor potential vanilloid 1 (TRPV1) channels. We show that in excised patches PtdIns $(4,5) \mathrm{P}_{2}$ and other phosphoinositides activate and the PIP ${ }_{2}$ scavenger poly-Lys inhibits TRPV1. TRPV1 currents undergo desensitization on exposure to high concentrations of capsaicin in the presence of extracellular $\mathrm{Ca}^{2+}$. We show that in the presence of extracellular $\mathrm{Ca}^{2+}$, capsaicin activates phospholipase C (PLC) in TRPV1-expressing cells, inducing depletion of both PtdIns $(4,5) \mathrm{P}_{2}$ and its precursor PtdIns(4)P (PIP). The PLC inhibitor U73122 and dialysis of PtdIns $(4,5) \mathrm{P}_{2}$ or PtdIns(4)P through the patch pipette inhibited desensitization of TRPV1, indicating that $\mathrm{Ca}^{2+}$-induced activation of PLC contributes to desensitization of TRPV1 by depletion of PtdIns(4,5) $\mathrm{P}_{2}$ and PtdIns(4)P. Selective conversion of PtdIns $(4,5) \mathrm{P}_{2}$ to PtdIns(4)P by a rapamycin-inducible PIP 2 5-phosphatase did not inhibit TRPV1 at high capsaicin concentrations, suggesting a significant role for PtdIns(4)P in maintaining channel activity. Currents induced by low concentrations of capsaicin and moderate heat, however, were potentiated by conversion of $\operatorname{PtdIns}(4,5) \mathrm{P}_{2}$ to $\mathrm{Ptd} \operatorname{Ins}(4) \mathrm{P}$. Increasing PtdIns $(4,5) \mathrm{P}_{2}$ levels by coexpressing phosphatidylinositol-4-phosphate 5-kinase inhibited TRPV1 at low but not at saturating capsaicin concentrations. These data show that at low capsaicin concentrations and other moderate stimuli, $\operatorname{PtdIns}(4,5) \mathrm{P}_{2}$ partially inhibits TRPV1 in a cellular context, but this effect is likely to be indirect, because it is not detectable in excised patches. We conclude that phosphoinositides have both inhibitory and activating effects on TRPV1, resulting in complex and distinct regulation at various stimulation levels.

Key words: TRPV1; TRP channel; phosphoinositides; $\mathrm{PIP}_{2}$; vanilloid; desensitization

\section{Introduction}

Transient receptor potential vanilloid 1 (TRPV1) channels are activated by warm temperatures, low $\mathrm{pH}$, and capsaicin, the pungent compound of chili peppers (Caterina et al., 1997). In nociceptive neurons, activation of phospholipase C (PLC)-coupled receptors by pro-inflammatory agents such as bradykinin, NGF, ATP, or chemokines sensitizes TRPV1 to subsequent activation by moderately low $\mathrm{pH}$, warm temperatures, and submaximal concentrations of capsaicin (Chuang et al., 2001; Tominaga et al., 2001; Moriyama et al., 2003; N. Zhang et al., 2005). This phenomenon underlies thermal hyperalgesia, the increased sensitivity to painful stimuli after tissue injury or inflammation. TRPV1 channels were reported to be inhibited by the phospholipid phosphatidylinositol 4,5-bisphosphate $\left[\operatorname{PtdIns}(4,5) \mathrm{P}_{2}\right]$, and relief from

Received Dec. 1, 2006; revised May 23, 2007; accepted May 24, 2007.

T.B., P.V., and A.B. were supported in part by the Intramural Research Program of the National Institute of Child Health and Human Development-National Institutes of Health. T.R. was supported by the American Heart Association, the Alexander and Alexandrine Sinsheimer Foundation, and the University of Medicine and Dentistry of New Jersey Foundation. The insightful comments of Dr. John Reeves are highly appreciated. The clones for the phosphatase recruitment system in the oocyte vector pEXO were kindly provided by Drs. Peter Enyedi and Gabor Czirjak (Semmelweis University, Budapest, Hungary).

*V.L. and B.T. contributed equally to this work.

Correspondence should be addressed to Dr. Tibor Rohacs, Department of Pharmacology and Physiology, University of Medicine and Dentistry of New Jersey-New Jersey Medical School, 185 South Orange Avenue, MSB H631, Newark, NJ 07103.E-mail: tibor.rohacs@umdnj.edu.

DOI:10.1523/JNEUROSCI.1866-07.2007

Copyright $\odot 2007$ Society for Neuroscience $\quad$ 0270-6474/07/277070-11\$15.00/0 this inhibition by PtdIns $(4,5) \mathrm{P}_{2}$ hydrolysis was proposed to mediate sensitization of TRPV1 by PLC-coupled agonists (Chuang et al., 2001). It is important to note that the potentiating effect of PtdIns $(4,5) \mathrm{P}_{2}$ hydrolysis was shown at low concentrations of capsaicin $(10-100 \mathrm{~nm})$ and moderately low $\mathrm{pH}$. The idea that $\operatorname{PtdIns}(4,5) \mathrm{P}_{2}$ inhibits TRPV1 was based on indirect experiments; the effects of phosphoinositides were not tested in excised patches directly (Chuang et al., 2001).

Most other mammalian TRP channels are activated by PtdIns (4,5) $\mathrm{P}_{2}$ (Hardie, 2007; Rohacs and Nilius, 2007; Voets and Nilius, 2007). The region that was proposed to be responsible for the inhibition of TRPV1 by $\operatorname{PtdIns}(4,5) \mathrm{P}_{2}$ is in the distal C terminus of TRPV1 (Prescott and Julius, 2003), which is not conserved among TRPV or other TRP channels (amino acids 777-820). This raises the possibility that the inhibitory effect of PtdIns $(4,5) \mathrm{P}_{2}$ builds on a more conserved activating effect of $\operatorname{PtdIns}(4,5) \mathrm{P}_{2}$ as proposed previously (Rohacs et al., 2005; Rohacs, 2007).

High concentrations of capsaicin desensitize TRPV1 currents in the presence of extracellular $\mathrm{Ca}^{2+}$ (Koplas et al., 1997; Mohapatra and Nau, 2003), an effect that may underlie the paradoxical use of capsaicin as an analgesic compound (Szallasi and Blumberg, 1999; Caterina and Julius, 2001). The calcium-dependent protein phosphatase calcineurin was proposed to mediate this desensitization (Docherty et al., 1996). The inhibition of desensitization by calcineurin inhibitors was partial (Mohapatra and 
Nau, 2005), suggesting that other pathways may also contribute to this phenomenon. Interestingly, $\operatorname{PtdIns}(4,5) \mathrm{P}_{2}$ synthesis was shown to be important for the recovery of TRPV1 currents from desensitization (Liu et al., 2005), a finding that was difficult to fit with the originally published inhibition of TRPV1 by $\operatorname{PtdIns}(4,5) \mathrm{P}_{2}$. The same report suggested that $\operatorname{PtdIns}(4,5) \mathrm{P}_{2}$ is depleted during the desensitization process, based on the inhibition of the PtdIns $(4,5) \mathrm{P}_{2}$-sensitive Kir2.1 channel. The mechanism of PtdIns $(4,5) \mathrm{P}_{2}$ depletion was not examined; neither was the effect of interfering with $\operatorname{PtdIns}(4,5) \mathrm{P}_{2}$ depletion on desensitization. A recent report showed that $\operatorname{PtdIns}(4,5) \mathrm{P}_{2}$ activates TRPV1 in excised patches (Stein et al., 2006). This finding challenges the inhibitory role of $\operatorname{PtdIns}(4,5) \mathrm{P}_{2}$ in the regulation of TRPV1, but it is compatible with the role of $\operatorname{PtdIns}(4,5) \mathrm{P}_{2}$ depletion in desensitization of TRPV1 currents.

Here, we show that PtdIns $(4,5) \mathrm{P}_{2}$, its precursor PtdIns(4)P (PIP), and other phosphoinositides activate TRPV1 in excised patches. After exposure to high capsaicin concentrations, $\mathrm{Ca}^{2+}$ flowing through TRPV1 activates PLC, and the resulting depletion of PtdIns(4,5) $\mathrm{P}_{2}$ and PtdIns(4)P limits channel activity, leading to desensitization. We also conclude that at low capsaicin concentrations, in addition to its importance in maintaining channel activity, PtdIns $(4,5) \mathrm{P}_{2}$ also partially inhibits TRPV1 in a cellular context. Our data show that the balance between the inhibitory and activating effects of PtdIns $(4,5) \mathrm{P}_{2}$ depends on the stimulation level of the channel.

\section{Materials and Methods}

Cell culture. Human embryonic kidney 293 (HEK293) cells were maintained in minimal essential medium solution (Invitrogen, San Diego, CA) supplemented with $10 \%$ fetal bovine serum (Invitrogen) and penicillin/streptomycin. The rat TRPV1 tagged with the myc epitope on the $\mathrm{N}$ terminus in pCDNA3 vector was transfected using the Effectene reagent (Qiagen, Chatsworth, CA). For the electrophysiology experiments in Figure 4 , transfection was confirmed by measuring fluorescence of cotransfected green fluorescent protein (GFP). For experiments with rapalog (see Figs. 6, 7), the cells were transfected with the myc-tagged TRPV1, the plasma membrane-targeted cyan fluorescent protein (CFP)-tagged FRB fragment of the mammalian target of rapamycin (FRB) (T2098L) containing three copies of FRB, and the red fluorescent protein (RFP)-tagged FK506 binding protein 12 (FKBP12) linked to the phosphatase domain of $\mathrm{PIP}_{2}$ 5-phosphatase (Varnai et al., 2006). For control experiments, the RFP-FKBP12-phosphatase domain was replaced with the RFP-tagged FKBP12 without the phosphatase domain.

Materials. $\mathrm{DiC}_{8}$ phosphoinositides were purchased from Echelon (Salt Lake City, UT) or Cayman Chemical (Ann Arbor, MI), and arachidonylstearyl (AASt) PtdIns $(4,5) \mathrm{P}_{2}$ was purchased from Biomol (Plymouth Meeting, PA). Rapamycin, menthol, capsaicin, and most other chemicals were from Sigma (St. Louis, MO). U73122 and U73343 were purchased from Alexis Biochemicals/Axxora Platform (San Diego, CA). The rapamycin analog (AP21967, rapalog) was provided by the Regulation Kits section of Ariad Pharmaceutical (Cambridge, MA).

Mammalian electrophysiology. Measurements were conducted 36-72 h after transfection in a solution containing (in $\mathrm{mM}$ ) $137 \mathrm{NaCl}, 5 \mathrm{KCl}, 1$ $\mathrm{MgCl}_{2}, 1 \mathrm{CaCl}_{2}, 10$ glucose, and 10 HEPES, $\mathrm{pH}$ adjusted to 7.4. The same solution was used for the fluorescence measurements (see below). Borosilicate glass pipettes (World Precision Instruments, Sarasota, FL) of 2-4 $\mathrm{M} \Omega$ resistance were filled with a solution containing (in $\mathrm{mM}$ ) 135 K-gluconate, $5 \mathrm{KCl}, 5 \mathrm{EGTA}, 1 \mathrm{MgCl}_{2}$, and $10 \mathrm{HEPES}$, pH adjusted to 7.2. For the experiments with rapalog (see Figs. 6, 7), the pipette solution was supplemented with $2 \mathrm{~mm}$ ATP. After formation of G $\Omega$-resistance seals, whole-cell configuration was established, and currents were measured at $-60 \mathrm{mV}$, using an Axopatch 200B amplifier (Molecular Devices, Union City, CA). Data were collected and analyzed with pClamp 9.0 software. Measurements were performed at room temperature $\left(19-24^{\circ} \mathrm{C}\right)$.

Electrophysiology in oocytes. Measurements were conducted on oocytes extracted from Xenopus laevis frogs using collagenase digestion. Oocytes were maintained in a solution containing (in $\mathrm{mM}$ ) $87.5 \mathrm{NaCl}, 5 \mathrm{KCl}, 1$ $\mathrm{MgCl}_{2}, 1.8 \mathrm{CaCl}_{2}$, and 5 HEPES. Expression of TRPV1, TRPV1 $\Delta 777-$ 820, PLC 83 , and phosphatidylinositol-4-phosphate 5-kinase (PIP5K) and the components of the $\mathrm{PIP}_{2}$ 5-phosphatase recruitment system was achieved by microinjection of linearized cRNA of these constructs in pGEMSH or pEXO vectors using a nanoliter-injector system (Warner Instruments, Hamden, CT). For two-electrode voltage-clamp (TEVC) measurements, thin-wall inner-filament-containing glass pipettes (World Precision Instruments) were filled with $3 \mathrm{M} \mathrm{KCl}$ in $1 \%$ agarose. Cells were perfused with a solution (ND96) containing (in mM) $96 \mathrm{NaCl}$, $2 \mathrm{KCl}, 1 \mathrm{MgCl}_{2}$, and 5 HEPES, pH adjusted to 7.4. In a subset of experiments (see Fig. 5), this solution was supplemented with $2 \mathrm{mM} \mathrm{CaCl}_{2}$ to measure desensitization. Currents were obtained using a GeneClamp 500B amplifier (Molecular Devices) either using a ramp protocol from -100 to $+100 \mathrm{mV}$ applied every second $(0.25 \mathrm{mV} / \mathrm{ms})$ or at constant holding at $-60 \mathrm{mV}$. Measurements were performed at room temperature $\left(19-21^{\circ} \mathrm{C}\right)$. Macropatch experiments were performed with borosilicate glass pipettes (World Precision Instruments) of $0.8-1.7 \mathrm{M} \Omega$ resistance filled with ND96. After establishing G $\Omega$-resistance seals on devitellinized surfaces of oocytes, inside-out configuration was established, and currents were measured using a ramp protocol from -100 to $+100 \mathrm{mV}$ applied every second. The main perfusing solution contained (in mM) $96 \mathrm{KCl}, 5 \mathrm{EGTA}$, and 10 HEPES, pH adjusted to 7.4. Currents were amplified with an Axopatch 200B unit (Molecular Devices) and analyzed with pClamp 9.0 software (Molecular Devices). To increase the stability of the excised patches, these measurements were performed at $17-18^{\circ} \mathrm{C}$, controlled with an SC-20 inline heater/cooler (Warner Instruments).

Fluorescence resonance energy transfer measurements. HEK cells were transfected with the CFP- and yellow fluorescent protein (YFP)-tagged PH domains of PLC $\delta 1$ (van der Wal et al., 2001) and TRPV1. Measurements were performed using a photomultiplier-based system mounted on an IX-71 (Olympus, Tokyo, Japan) inverted microscope, equipped with a DeltaRAM excitation light source (Photon Technology International, Birmingham, NJ). For the fluorescence resonance energy transfer (FRET) measurements, excitation wavelength was $425 \mathrm{~nm}$, and emission was detected parallel at 480 and $535 \mathrm{~nm}$ using two interference filters and a dichroic mirror to separate the two emission wavelengths. Data were collected using the Felix software (Photon Technology International), and the ratio of traces obtained at the two different wavelengths, correlating with FRET, were plotted (van der Wal et al., 2001). Measurements were performed at room temperature $\left(19-24^{\circ} \mathrm{C}\right)$.

Confocal microscopy. HEK cells were transfected with TRPV1 and the GFP-tagged OSH2-tandem PH domain that is targeted to the plasma membrane through binding to PtdIns(4)P (Roy and Levine, 2004). Experiments were performed $2 \mathrm{~d}$ after transfection. PtdIns(4)P depletion was assessed by the translocation of the PH-OSH2-GFP from the plasma membrane to the cytoplasm. The cells were observed with a Zeiss (Oberkochen, Germany) LSM-510 confocal microscope, equipped with an argon laser $(488 \mathrm{~nm})$, in the Confocal Imaging Facility of the New Jersey Medical School. Images were saved as TIFF files and were analyzed with the ImageJ software. The PH domain of OSH2 (256-424) was amplified from Saccharomyces cerevisiae DNA (American Type Culture Collection, Manassas, VA). Two separate PCRs were performed to achieve tandem $\mathrm{PH}$ domains with a linker between them. The OSH2tandem $\mathrm{PH}$ domain was subcloned into pEGFP-C1 plasmid (Clontech, Moutain View, CA).

Measurement of inositol phosphates. Inositol phosphates were measured as described previously (Nakanishi et al., 1995). Briefly, HEK cells transfected with TRPV1 were incubated with ${ }^{3} \mathrm{H}$-inositol for $24 \mathrm{~h}$. The cells were washed and stimulated with $2 \mu \mathrm{M}$ capsaicin for various time periods in the presence of $1.2 \mathrm{~mm}$ extracellular $\mathrm{Ca}^{2+}$, the reaction was terminated with the addition of ice-cold perchloric acid, and inositol phosphates were separated on HPLC, as described previously (Nakanishi et al., 1995).

Data analysis. Dose-response relationships in response to $\mathrm{diC}_{8}$ $\mathrm{PI}(4,5) \mathrm{P}_{2}$ were analyzed in the following way. A reference concentration of $\mathrm{PI}(4,5) \mathrm{P}_{2}$ was applied repetitively throughout the measurement to 
correct for changes in the responsiveness of the patch. The data points were fitted with the Hill equation using the Microcal (Amherst, MA) Origin software to obtain the $\mathrm{EC}_{50}$ values, the Hill coefficients, and the maximal responses.

Data for all figures were expressed as mean \pm SEM. Statistical significance was evaluated by $t$ test.

\section{Results}

\section{Phosphoinositides activate TRPV1 in} excised patches

We studied the effects of phosphoinositides in excised patches on TRPV1 channels expressed in Xenopus oocytes. We found that poly-lysine, a poly-cation that chelates PtdIns $(4,5) \mathrm{P}_{2}$, inhibited the channels (Fig. 1), suggesting that endogenous negatively charged lipids keep the channels open after excision. After inhibition by poly-Lys, the channels were reactivated by both the long acyl-chain AASt PtdIns $(4,5) \mathrm{P}_{2}$ (Fig. $1 A$ ) and the short acyl-chain diC $_{8} \operatorname{PtdIns}(4,5) \mathrm{P}_{2}$ (Fig. $1 B, C$ ). Other $\mathrm{diC}_{8}$ phosphoinositides [PtdIns(4)P, $\operatorname{PtdIns}(3,4,5) \mathrm{P}_{3}, \operatorname{PtdIns}(3,4) \mathrm{P}_{2}, \operatorname{PtdIns}(3,5) \mathrm{P}_{2}$, and PtdIns(5)P] also activated TRPV1 (Fig. $1 B)$. We also tested PtdIns, which at $100 \mu \mathrm{M}$ made the patches unstable and the measurements noisy. The effect of PtdIns was $<10 \%$ of that of PtdIns $(4,5) \mathrm{P}_{2}$ (data not shown).

$\operatorname{PtdIns}(3,4,5) \mathrm{P}_{3}$ and $\operatorname{PtdIns}(3,4) \mathrm{P}_{2}$, the products of phosphoinositide 3 '-kinases, as well as PtdIns(5)P and $\operatorname{PtdIns}(3,5) \mathrm{P}_{2}$ are found in the plasma membrane at concentrations much lower than those of PtdIns(4,5) $\mathrm{P}_{2}$ (Fruman et al., 1998); thus, their role in maintaining TRPV1 activity is unlikely under physiological conditions. $\operatorname{PtdIns}(4) \mathrm{P}$, the precursor of $\operatorname{PtdIns}(4,5) \mathrm{P}_{2}$, in contrast, is found in the plasma membrane in quantities similar to that of PtdIns(4,5) $\mathrm{P}_{2}$ (Fruman et al., 1998). To better characterize the effects of PtdIns $(4,5) \mathrm{P}_{2}$ and PtdIns(4)P, we performed dose-response measurements with these two lipids (Fig. 1C). PtdIns(4)P had a very similar maximal effect to $\operatorname{PtdIns}(4,5) \mathrm{P}_{2}$, but its $\mathrm{EC}_{50}$ was shifted to the right. Also, the apparent affinity of TRPV1 for PtdIns(4)P and PtdIns $(4,5) \mathrm{P}_{2}$ was slightly lower at negative than at positive voltages, similarly to TRPM8 (Rohacs et al., 2005). PtdIns(4,5) $\mathrm{P}_{2}$ at $+100 \mathrm{mV}$ had an $\mathrm{EC}_{50}$ of $4.9 \pm 1.3 \mu \mathrm{M}$ and a Hill coefficient of $0.69 \pm 0.09$. At $-100 \mathrm{mV}$, the same values were $11.1 \pm 3.5 \mu \mathrm{M}$ and $0.69 \pm 0.10$. For PtdIns(4)P at $+100 \mathrm{mV}$, the $\mathrm{EC}_{50}$ was $32.4 \pm 13.1 \mu \mathrm{M}$ and the Hill coefficient was $0.80 \pm 0.13$. At $-100 \mathrm{mV}$, the same values were $70.2 \pm 7.1 \mu \mathrm{M}$ and $0.84 \pm 0.11$.

The experiments in Figure 1 were performed in the presence of high concentrations of capsaicin in the patch pipette [ $1 \mu \mathrm{M}(A$, $B)$ and $10 \mu \mathrm{M}(C)]$. Because the proposed inhibitory effect of PtdIns $(4,5) \mathrm{P}_{2}$ is observed at low agonist concentrations (Chuang et al., 2001), we also tested the effect of $\operatorname{PtdIns}(4,5) \mathrm{P}_{2}$ in the presence of $100 \mathrm{~nm}$ capsaicin, a concentration corresponding to low stimulus strength in oocytes. Under these conditions, $\mathrm{diC}_{8}$

A
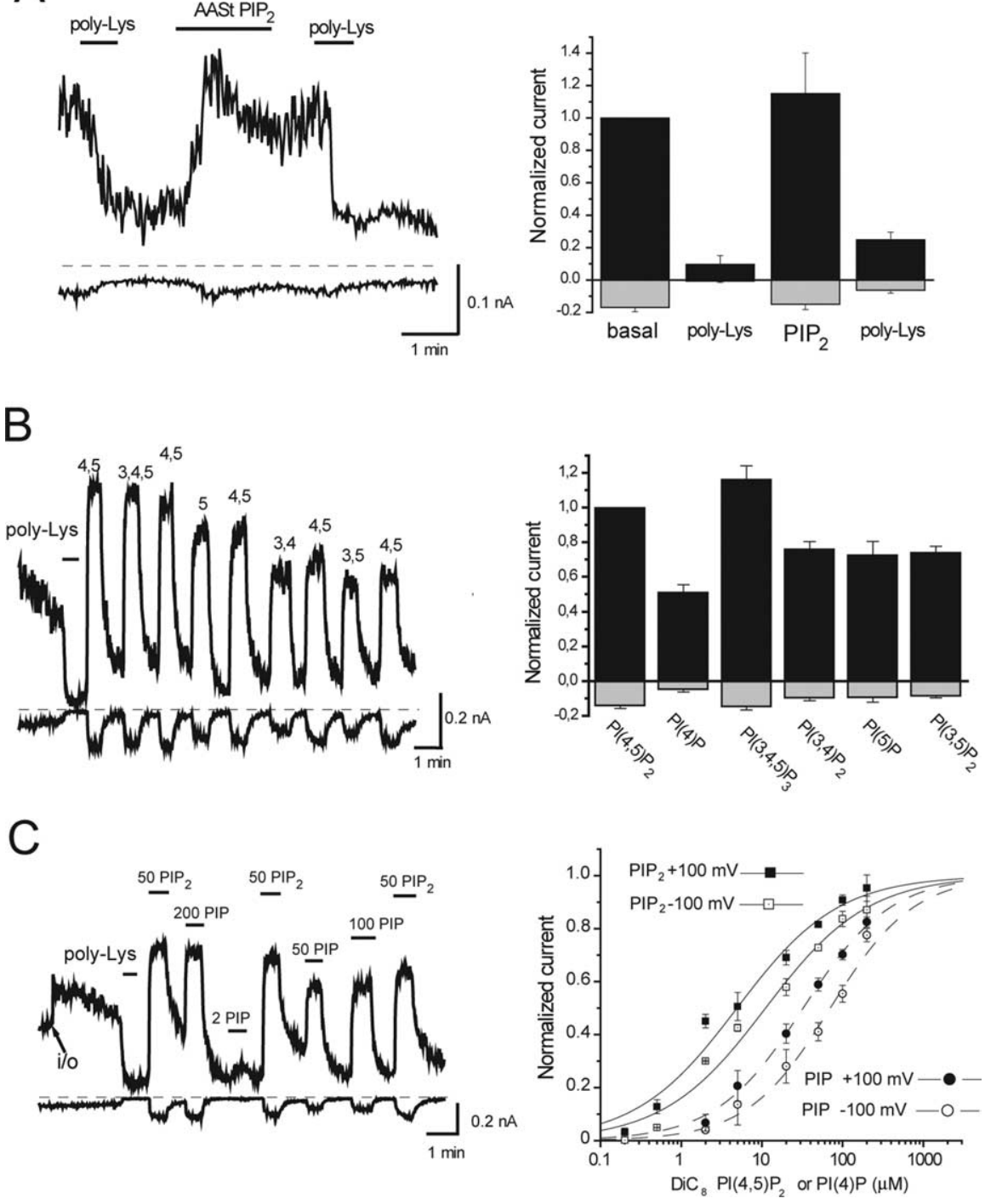

Figure 1. Phosphoinositides activate TRPV1 channels. Currents were measured in large membrane patches excised from 0ocytes expressing TRPV1 using the ramp protocol described in Materials and Methods. Representative traces show currents at the intracellular surface of the patch in the presence of $1 \mu \mathrm{m}$ capsaicin $(\boldsymbol{A}, \boldsymbol{B})$ and $10 \mu \mathrm{m}$ capsaicin $(\boldsymbol{C})$ in the patch pipette. $\boldsymbol{A}$, Effect of the long-chain AASt Ptdlns $(4,5) \mathrm{P}_{2}(5 \mu \mathrm{m})$ and poly-L-lysine (1 and $\left.30 \mu \mathrm{g} / \mathrm{ml}\right)$ for the first and second applications, respectively +100 and $-100 \mathrm{mV}\left[n=7-12\right.$, except Ptdlns $(5) \mathrm{P}_{2}$, which is $\left.n=3\right]$ for the effects of different phosphoinositides compared with $\mathrm{PIP}_{2}$ and PIP. poly-Lys, Poly-t-lysine.

PtdIns $(4,5) \mathrm{P}_{2}$ still activated and poly-Lys inhibited TRPV1 (supplemental Fig. 1, available at www.jneurosci.org as supplemental material). We also tried various concentrations of poly-Lys $(0.1-30 \mu \mathrm{g} / \mathrm{ml})$ and an antibody against $\operatorname{PtdIns}(4,5) \mathrm{P}_{2}$; none of these activated TRPV1 currents in excised patches in the presence of low- or high-capsaicin stimuli (data not shown). We conclude that in excised patches, PtdIns $(4,5) \mathrm{P}_{2}$ activates TRPV1 regardless of the agonist concentration, confirming the results of Stein et al. (2006).

\section{Capsaicin activates PLC in cells expressing TRPV1}

First, we used a FRET-based method (van der Wal et al., 2001; Rohacs et al., 2005), to show that capsaicin induces depletion of PtdIns $(4,5) \mathrm{P}_{2}$ in the presence of extracellular $\mathrm{Ca}^{2+}$ in TRPV1expressing cells (Fig. $2 \mathrm{~A}$ ). This method is based on the transloca- 
A

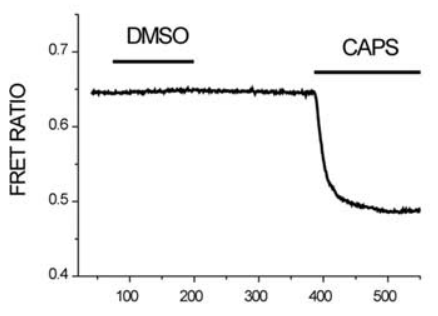

C

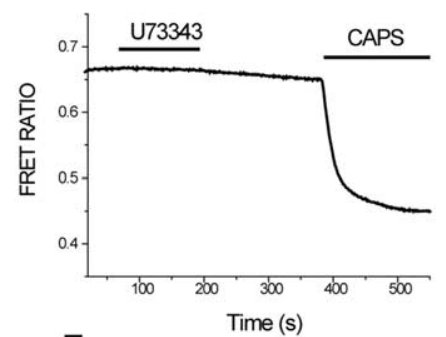

E

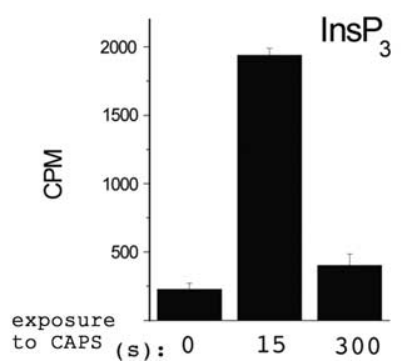

B

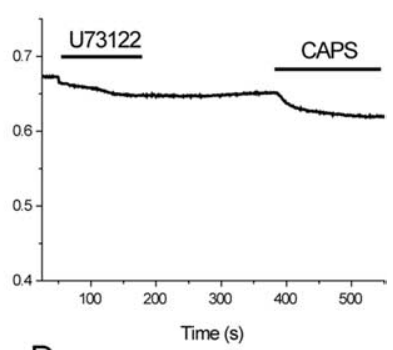

D

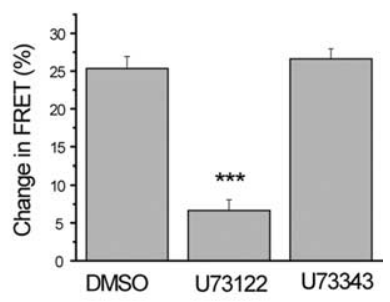

F

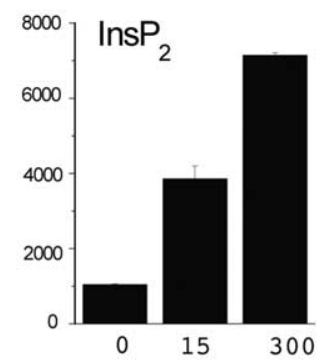

Figure 2. Capsaicin activates PLC in TRPV1-expressing cells. $\boldsymbol{A}-\boldsymbol{D}$, Fluorescence was measured in HEK 293 cells expressing TRPV1 and the CFP- and YFP-tagged PLC $\delta 1$ PH domains, as described in Materials and Methods. (ells were pretreated with DMSO $(\boldsymbol{A}), 3 \mu \mathrm{m}$ U73122 (B), or $3 \mu \mathrm{M}$ U73343 (C) for $2 \mathrm{~min}$, and then $1 \mu \mathrm{m}$ capsaicin (CAPS) was applied, as indicated by the horizontal lines. The extracellular medium contained $1 \mathrm{~mm} \mathrm{Ca}^{2+}$. The change in FRET ratio (D) was measured by dividing the value 2 min after the application of capsaicin with the FRET ratio value before the application of capsaicin to result $Q$, and then $100-(100 \times Q)$ was plotted $(n=14-17) .{ }^{* * *} p<0.005 . E$, $F$, HEK cells expressing TRPV1 were incubated with ${ }^{3} \mathrm{H}$-inositol, as described in Materials and Methods, and stimulated with $2 \mu \mathrm{m}$ capsaicin for the time periods indicated. Inositol phosphates were extracted and separated on HPLC, and the radioactivity was plotted for $\mathrm{IP}_{3}\left(\operatorname{Ins}_{3} ; \boldsymbol{E}\right)$ and $\mathrm{IP}_{2}\left(\operatorname{InsP}_{2} ; \boldsymbol{F}\right)$.

tion of the CFP/YFP-tagged PLC $\delta 1 \mathrm{PH}$ domain from the plasma membrane to the cytoplasm after PtdIns $(4,5) \mathrm{P}_{2}$ depletion, which is shown in the figure as downward deflection of the FRET ratio traces. Although this method has been claimed to also monitor changes in inositol-1,4,5-trisphosphate ( $\mathrm{IP}_{3}$ or $\mathrm{InsP}_{3}$ ) levels (Hirose et al., 1999), it is clear that the translocation of these fluorescent reporter proteins may happen after $\operatorname{PtdIns}(4,5) \mathrm{P}_{2}$ depletion without formation of $\mathrm{IP}_{3}$ (Suh et al., 2006; Varnai et al., 2006).

Depletion of PtdIns $(4,5) \mathrm{P}_{2}$ thus can happen either by dephosphorylation by phosphatase enzymes (Suh et al., 2006; Varnai et al., 2006) or via degradation by PLC (Varnai and Balla, 1998). To differentiate between these two possibilities, we examined the effect of U73122, an inhibitor of PLC, on the $\operatorname{PtdIns}(4,5) \mathrm{P}_{2}$ hydrolysis induced by capsaicin. We used $3 \mu \mathrm{M}$ U73122 for 2 min, followed by a $3 \mathrm{~min}$ wash, a similar protocol that was reported to minimize the direct effect of U73122 on PtdIns(4,5) $\mathrm{P}_{2}$ levels monitored with the PLC $\delta 1 \mathrm{PH}$ domain (Horowitz et al., 2005). In our hands, even in this protocol U73122 induced a small decrease in the FRET signal. This could be attributable to the reported variability between U73122 batches (Balla, 2001). More impor-
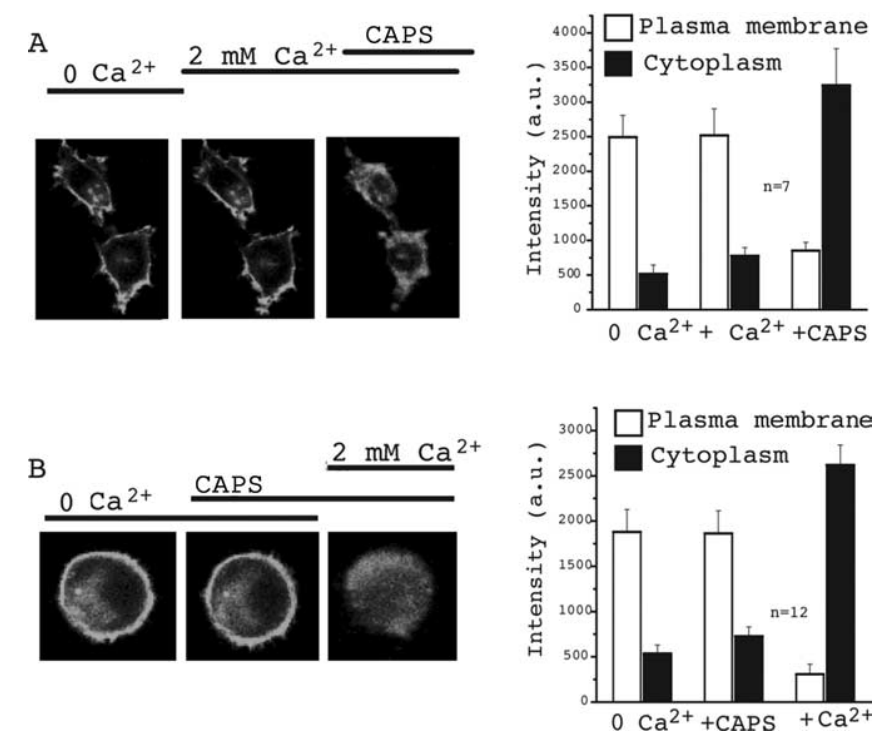

Figure 3. Capsaicin (CAPS) induces Ptdlns(4)P depletion in the presence of extracellular $\mathrm{Ca}^{2+}$. HEK cells were transfected with TRPV1 and the GFP-tagged OSH2-tandem PH domain that is targeted to the plasma membrane through binding to Ptdlns(4)P. Ptdlns(4)P depletion was assessed by the translocation of the PH-OSH2-GFP from the plasma membrane to the cytoplasm. $\boldsymbol{A}$, The images show fluorescence of two representative cells in control $\left(0 \mathrm{Ca}^{2+}\right), 2$ min after the addition of $2 \mathrm{~mm} \mathrm{Ca}^{2+}$, and $2 \mathrm{~min}$ after application of $1 \mu \mathrm{m}$ capsaicin. The right panel shows summary of the data. An area was selected on the plasma membrane (more intense GFP) as well as in the cytoplasm (less intense), and the average pixel intensity in the area of selection was represented in arbitrary units (a.u.). $\boldsymbol{B}$ is the same as $\boldsymbol{A}$, but the order of application of capsaicin and $\mathrm{Ca}^{2+}$ is reversed.

tantly, capsaicin applied after pretreatment with U73122 induced only a negligible PtdIns $(4,5) \mathrm{P}_{2}$ hydrolysis (Fig. $2 B, D$ ), whereas the inactive analog $\mathrm{U} 73343$ had no effect (Fig. $2 C, D$ ).

We also measured $\mathrm{IP}_{3}$ production in response to capsaicin. Increased $\mathrm{IP}_{3}$ is only expected if $\operatorname{PtdIns}(4,5) \mathrm{P}_{2}$ is broken down by PLC, but not if it is dephosphorylated by phosphatases. We found that capsaicin increased $\mathrm{IP}_{3}$ and $\mathrm{IP}_{2}$ production (Fig. $2 E, F$ ), confirming PLC activation. Fifteen seconds after the application of capsaicin, both $\mathrm{IP}_{3}$ and its degradation product $\mathrm{IP}_{2}$ were elevated. Five minutes after the application of capsaicin, $\mathrm{IP}_{2}$ levels further increased, whereas $\mathrm{IP}_{3}$ returned to levels slightly above control (Fig. 2E,F), which is compatible with dephosphorylation of $\mathrm{IP}_{3}$ to $\mathrm{IP}_{2}$ in the cytoplasm.

The dimerized, GFP-tagged $\mathrm{PH}$ domain of OSH2, a yeast homolog of the oxysterol-binding protein, has been used to monitor PtdIns(4)P levels (Roy and Levine, 2004). We used this technique to examine whether activation of TRPV1 by capsaicin also leads to PtdIns(4)P depletion. Figure 3 shows that this construct localizes mainly to the plasma membrane in resting cells. Application of capsaicin in the presence of $\mathrm{Ca}^{2+}$ induced a marked translocation of GFP fluorescence to the cytoplasm (Fig. 3A). Stimulation of TRPV1-expressing HEK cells with $1 \mu \mathrm{M}$ capsaicin in the absence of extracellular $\mathrm{Ca}^{2+}$ did not change the localization of GFP fluorescence (Fig. 3B). Increasing extracellular $\mathrm{Ca}^{2+}$ to 2 $\mathrm{mM}$, in the continued presence of capsaicin, induced a marked translocation of the GFP fluorescence to the cytoplasm (Fig. 3B). These data show that capsaicin, in addition to $\operatorname{PtdIns}(4,5) \mathrm{P}_{2}$ breakdown, also induces PtdIns(4)P depletion in the plasma membrane, and this effect depends on the presence of extracellular $\mathrm{Ca}^{2+}$. 

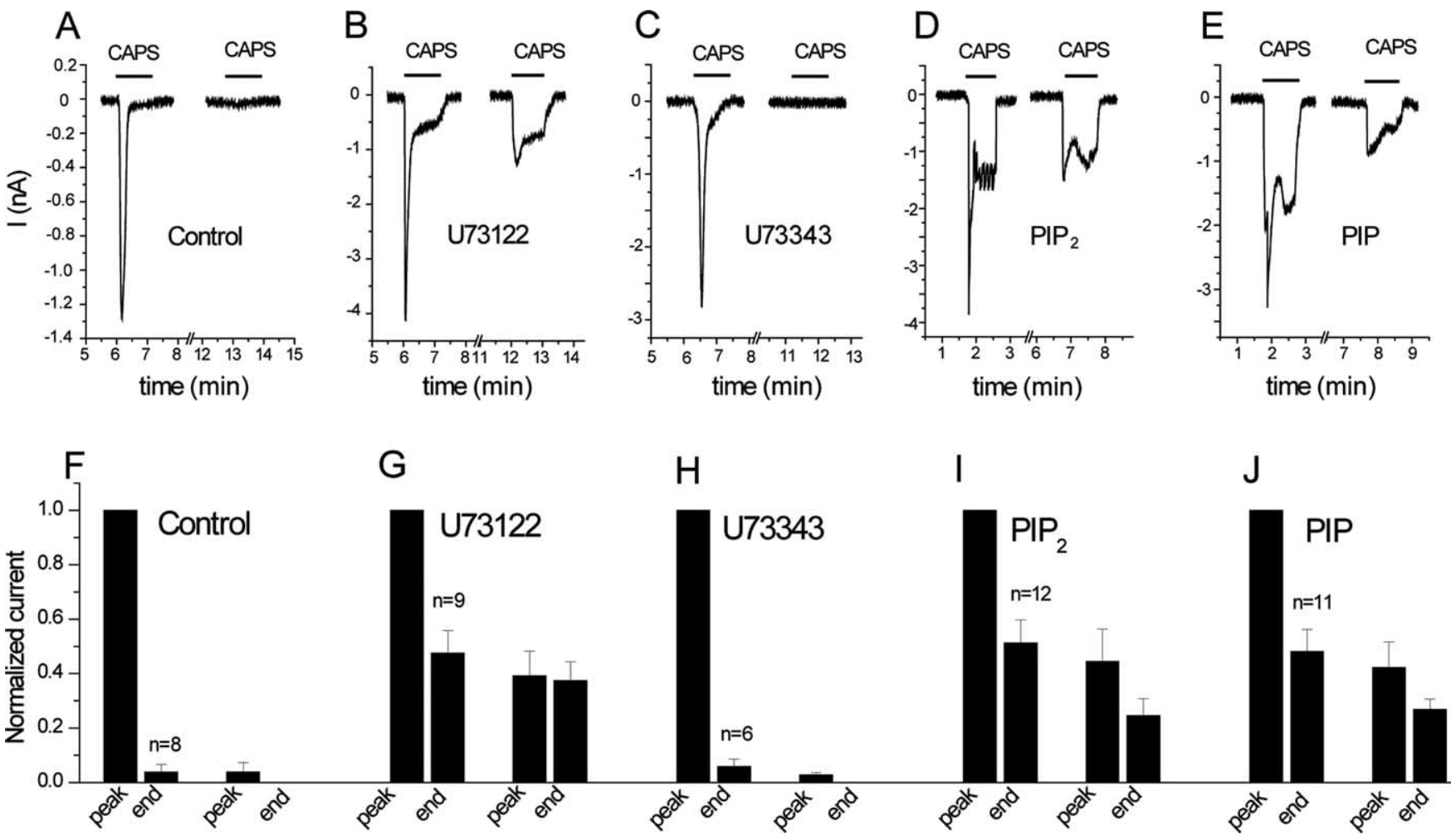

Figure 4. Desensitization of TRPV1 currents is inhibited by the PLC blocker U73122 and by Ptdlns $(4,5) \mathrm{P}_{2}$ and Ptdlns(4)P. Whole-cell patch-clamp measurements were performed at $-60 \mathrm{mV}$ on HEK cells expressing TRPV1, as described in Materials and Methods. $\boldsymbol{A}-\boldsymbol{E}$, Representative measurements. $\boldsymbol{F}$-J, Statistics. $\boldsymbol{A}-\boldsymbol{C}, \boldsymbol{F}-\boldsymbol{H}$, (ells were preincubated with vehicle $(\boldsymbol{A}, \boldsymbol{F}), 3 \boldsymbol{\mu m} \mathrm{U} 73122(\boldsymbol{B}, \boldsymbol{G})$,

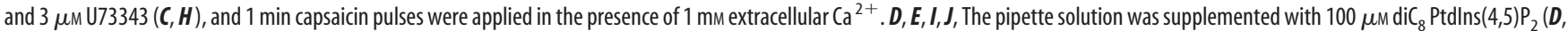
I) or $100 \mu \mathrm{m} \mathrm{DiC}{ }_{8} \mathrm{Ptdlns}(4) \mathrm{P}(\boldsymbol{E}, J)$. The first capsaicin pulse was applied in all experiments 5-10 min after the establishment of the whole-cell configuration. The data were normalized to the first peak current, and the current amplitudes were plotted for the end of the first capsaicin pulse, peak current of the second capsaicin pulse, and the end of the second capsaicin pulse ( $n=6-12)$. CAPS, Capsaicin.

Interfering with phosphoinositide depletion inhibits desensitization of TRPV1 currents

Next, we performed whole-cell patch-clamp experiments in HEK cells expressing TRPV1, to test the effects of PLC inhibition and phosphoinositides on desensitization of TRPV1. We have measured TRPV1 currents at $-60 \mathrm{mV}$ in response to two subsequent 1-min-long capsaicin pulses in the presence of $1 \mathrm{~mm}$ extracellular $\mathrm{Ca}^{2+}$. By the end of the first pulse, currents decreased to almost zero, and by the end of the second pulse, there was invariably no current in control cells (Fig. $4 A, F$ ). This measurement was performed without added ATP in the internal solution in the patch pipette; the lack of recovery between the two capsaicin pulses is consistent with previous reports showing requirement for ATP for the recovery from desensitization (Liu et al., 2005). After pretreatment with U73122, TRPV1 currents desensitized much less; there was $\sim 40 \%$ of the peak current left at the end of the second capsaicin pulse (Fig. $4 B, G$ ). The inactive analog U73343 did not have any effect on the desensitization (Fig. 4C,H). We used the same protocol for application of U73122 for the current measurements as for the FRET experiments. U73122 itself induced a small transient inward current in 6 of 12 cells (data not shown).

Inhibition of PLC interferes with various downstream processes in addition to depleting phosphoinositides. To examine the involvement of phosphoinositide depletion more directly, we included either PtdIns(4,5) $\mathrm{P}_{2}$ (Fig. $4 D, I$ ) or its precursor PtdIns(4)P (Fig. 4E,J) in the whole-cell patch pipette and tested their effects on desensitization. Both phosphoinositides inhibited desensitization of TRPV1 currents to a similar extent to U73122.
The initial rapid decline of the current was not affected by any of these manipulations, which is compatible with the involvement of other mechanisms, such as calcineurin (Mohapatra and Nau, 2005) in desensitization of TRPV1 currents.

As a negative control, we included PtdIns in the pipette, because this compound had minimal effect on TRPV1 in excised patches. In all four measurements, in which $\mathrm{diC}_{8}$ PtdIns $(100 \mu \mathrm{M})$ was included in the patch pipette, the capsaicin-induced current decreased to zero by the end of the first 60 s capsaicin pulse (data not shown). Similarly to excised patches, however, the whole-cell seals were unstable, preventing the application of multiple capsaicin pulses with PtdIns in the pipette. The level of desensitization correlates with current amplitudes; higher-amplitude currents tend to desensitize faster and more completely, presumably because of the larger $\mathrm{Ca}^{2+}$ influx. The amplitude of the capsaicininduced currents was $2.12 \pm 0.47 \mathrm{nA}(n=8)$ in control measurements, $3.48 \pm 0.75(n=9)$ in U73122-treated cells, and $2.42 \pm$ $0.49(n=6)$ in U73343-treated cells. The amplitude of the capsaicin-induced currents was $3.32 \pm 0.49(n=12)$ in cells dialyzed with PtdIns $(4,5) \mathrm{P}_{2}$, and $3.32 \pm 0.49 \mathrm{nA}(n=11)$ in cells dialyzed with PtdIns(4)P. Because both the U73122-treated and PtdIns $(4,5) \mathrm{P}_{2}$ or PtdIns(4) $\mathrm{P}$ dialyzed cells had, on average, larger amplitudes than controls, the differences in current amplitudes cannot account for the inhibition of desensitization.

We also attempted to reconstitute desensitization of TRPV1 currents in Xenopus oocytes. TRPV1 currents in oocytes showed slow and incomplete desensitization (Fig. 5), making this model system suitable for testing the effect of heterologously expressed PLC isoforms. When we coexpressed PLC 83 , a highly $\mathrm{Ca}^{2+}$ sen- 


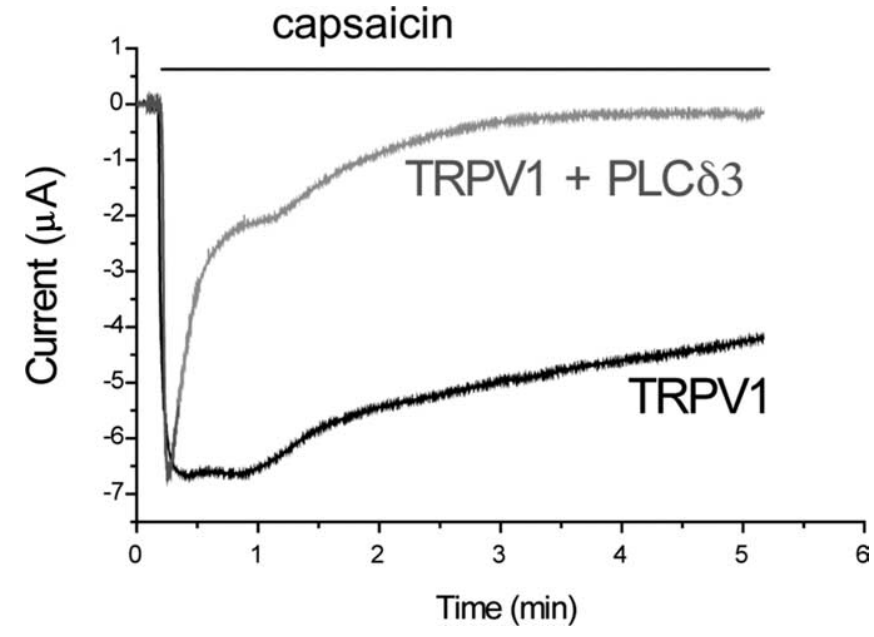

Figure 5. Coexpression of PLC $\delta 3$ accelerates desensitization of TRPV1 currents in oocytes. TEVC measurements were performed in Xenopus 0ocytes at a $-60 \mathrm{mV}$ holding potential, as described in Materials and Methods. Traces representing desensitization kinetics of oocytes expressing TRPV1 and those coexpressing PLC $\delta 3$ and the channel are shown; 00cytes were stimulated with $5 \mu \mathrm{m}$ capsaicin, in the presence of $2 \mathrm{~mm}$ calcium. See statistics in Results.

sitive PLC isoform, desensitization became faster and more complete (Fig. 5). The residual current after $5 \mathrm{~min}$ of capsaicin application was $38.0 \pm 4.4 \%$ of the peak current for control, whereas the same value was $9.9 \pm 2.1 \%$ for the PLC $\delta 3$-expressing oocytes ( $n=10$ for both groups). This measurement was performed at a constant $-60 \mathrm{mV}$ holding potential. The contribution of the endogenous $\mathrm{Ca}^{2+}$-activated $\mathrm{Cl}^{-}$current was minimal, because ionomycin did not induce any current at this voltage (supplemental Fig. 2A, available at www.jneurosci.org as supplemental material). Because activation of PLC produces $\mathrm{IP}_{3}$ that releases $\mathrm{Ca}^{2+}$ from intracellular stores, the measurements shown in Figure 5 were conducted on cells also expressing the type- $1 \mathrm{IP}_{3}$ 5 -phosphatase. This enzyme inactivates $\mathrm{IP}_{3}$, preventing the further rise in cytoplasmic calcium caused by $\mathrm{Ca}^{2+}$ release, which is presumably larger in PLC $\delta 3$-expressing cells, and thus could cause differences in desensitization. In control experiments, the $\mathrm{IP}_{3}$ phosphatase completely eliminated the $\mathrm{Ca}^{2+}$-induced $\mathrm{Cl}^{-}$ current in response to carbachol, in oocytes expressing the M1 muscarinic receptor and this enzyme (supplemental Fig. $2 B$, available at www.jneurosci.org as supplemental material). PLC $\delta 3$ coexpression also accelerated desensitization of TRPV1 in oocytes not expressing the $\mathrm{IP}_{3}$ phosphatase (data not shown).

Similarly to TRPM8 (Rohacs et al., 2005), the kinetics of desensitization of TRPV1 in oocytes is slower than that observed in mammalian cells. There are several differences that may account for such discrepancies; oocytes, for example, have a much lower surface-to-volume ratio, therefore the overall $\mathrm{Ca}^{2+}$ increase in the cytoplasm maybe smaller than in mammalian cells. It is also possible that oocytes have lower levels of PLC $\delta$ isoforms than mammalian cells. Also, the experiments shown in Figure 4 for HEK cells were performed without added ATP in the pipette solution that accelerates desensitization (Liu et al., 2005). In the oocyte experiments, the agarose in the recording electrodes prevents loss of intracellular ATP, which may also contribute to the slower desensitization.

We have shown that Ptdins(4)P activates TRPV1 in excised patches (Fig. $1 B, C$ ) and it is similarly effective to $\operatorname{PtdIns}(4,5) \mathrm{P}_{2}$ in inhibiting desensitization (Fig. $4 D, E, I, J$ ). We also have shown that capsaicin-induced activation of TRPV1 depleted PtdIns(4)P in the presence of extracellular $\mathrm{Ca}^{2+}$ (Fig. 3). PtdIns(4)P is also a substrate for PLC (Rebecchi and Pentyala, 2000), and it is known to be depleted during G-protein-coupled receptor- or calciummediated (ionomycin-induced) activation of PLC (Balla et al., 2005; Horowitz et al., 2005). PtdIns(4)P is found in quantities comparable to PtdIns $(4,5) \mathrm{P}_{2}$ in the plasma membrane (Fruman et al., 1998), raising the possibility that PtdIns(4)P, in addition to PtdIns $(4,5) \mathrm{P}_{2}$, also plays a role in maintaining TRPV1 activity. To test this possibility, we used the recently reported rapamycininducible $\mathrm{PIP}_{2}$ 5-phosphatase recruitment system to deplete PtdIns(4,5) $\mathrm{P}_{2}$ by converting it to PtdIns(4)P (Varnai et al., 2006). Briefly, this technique is based on the rapamycin-inducible translocation of the phosphatase domain of the type IV $\mathrm{PIP}_{2}$ 5-phosphatase to the plasma membrane, where it rapidly depletes PtdIns $(4,5) \mathrm{P}_{2}$ and inhibits the $\mathrm{PIP}_{2}$-sensitive TRPM8 (Varnai et al., 2006) and KCNQ2/3 (Suh et al., 2006) channels. The rapamycin analog (AP21967, rapalog) did not inhibit currents elicited by $1 \mu \mathrm{M}$ capsaicin (Fig. 6A) in HEK cells expressing TRPV1 and the rapamycin-inducible $\mathrm{PIP}_{2} 5$-phosphatase constructs. In these experiments, we used rapalog instead of rapamycin, because rapamycin induced a transient inhibition of TRPV1 currents in control experiments (FKBP12 expressed without the phosphatase domain), an effect that was not seen with rapalog. These experiments were performed using a mutant form of FRB (T2098L) as recommended for rapalog (Varnai et al., 2006) and in the absence of extracellular $\mathrm{Ca}^{2+}$ to prevent desensitization. Rapalog promptly and completely inhibited TRPM8 in control measurements (Fig. 6C), similarly to rapamycin (Varnai et al., 2006). These data are compatible with the notion that in addition to $\operatorname{PtdIns}(4,5) \mathrm{P}_{2}$, its precursor PtdIns(4)P also plays a role in maintaining TRPV1 channel activity. Other explanations for the lack of effect of rapalog-induced $\mathrm{PIP}_{2}$ depletion, such as inability of the phosphatase to access $\operatorname{PtdIns}(4,5) \mathrm{P}_{2}$ molecules bound to the channel, however, cannot be completely excluded.

\section{PtdIns $(4,5) \mathrm{P}_{2}$ partially inhibits TRPV1 at low stimulation strength}

We also tested the effect of rapalog on currents induced by low concentrations of capsaicin. Figure $6 B$ shows that rapalog further activated currents elicited by $1 \mathrm{nM}$ capsaicin. Rapalog had no significant effect in cells expressing TRPV1 and the control constructs (Fig. $6 B$ ) for the 5-phosphatase translocation system: FRB in the plasma membrane and FKBP12 in the cytoplasm, lacking the 5-phosphatase domain (Varnai et al., 2006). To achieve low stimulation strength, we used $1 \mathrm{nM}$ capsaicin in these experiments, which is lower than the usual "low" capsaicin concentration used in HEK cells $(\sim 10 \mathrm{~nm})$, because the capsaicin dose response in HEK cells expressing TRPV1 and the rapamycininducible phosphatase recruitment system was shifted to the left. This left shift was also observed in the control cells, expressing FRB and FKBP, without the phosphatase (supplemental Fig. 3, available at www.jneurosci.org as supplemental material), indicating that the dose-response shift was not attributable to altered PtdIns $(4,5) \mathrm{P}_{2}$ levels but rather the presence of other components of the recruitment system. Although these data have to be interpreted with some caution because of the altered sensitivity of TRPV1, they confirm the inhibitory effect of $\operatorname{PtdIns}(4,5) \mathrm{P}_{2}$ at low stimulation strength that was suggested previously (Chuang et al., 2001).

We also performed similar experiments in Xenopus oocytes expressing TRPV1 and the phosphatase recruitment system. In oocytes, capsaicin sensitivity of TRPV1 was not significantly altered by these constructs, yet rapamycin further increased currents evoked by low capsaicin concentration (100 nM) and had no 
effect on currents induced by high capsaicin $(1 \mu \mathrm{M})$ (supplemental Fig. 4, available at www.jneurosci.org as supplemental material). Note that the dose response of TRPV1 to capsaicin is shifted to the right in Xenopus oocytes (Caterina et al., 1997) when compared with TRPV1 expressed in mammalian cells (Tominaga et al., 1998); thus, to obtain low stimulation strength, we applied $100 \mathrm{~nm}$ capsaicin in the oocyte experiments.

Heat is probably the most important physiological stimulus of TRPV1, and PtdIns $(4,5) \mathrm{P}_{2}$ depletion was also reported to sensitize these channels to activation by heat (Chuang et al., 2001). Thus, we examined the effect of rapalog-induced PtdIns $(4,5) \mathrm{P}_{2}$ depletion on TRPV1 currents elicited by moderate heating. Currents elicited by increasing the temperature to $\sim 42^{\circ} \mathrm{C}$ were further increased by rapalog in HEK cells expressing the phosphatase recruitment system (Fig. $7 A$ ), but not in control cells (Fig. 7B). This temperature increase constitutes a moderate activation level, because the currents were similar in amplitude to those elicited by 1 nM capsaicin, and were much smaller than those induced by $1 \mu \mathrm{M}$ capsaicin.

Next, we examined the effect of coexpressing PIP5K type $\mathrm{I} \beta$, an enzyme that was shown to increase PtdIns $(4,5) \mathrm{P}_{2}$ levels (Lin et al., 2005) and affect PtdIns $(4,5) \mathrm{P}_{2}$ sensitive ion channels (Shyng et al., 2000). PIP5K inhibited TRPV1 channel activity induced by decreasing $\mathrm{pH}$ to 6.4 and 5.5 in Xenopus oocytes (Fig. 8A). The inhibition was more prevalent at the more moderate stimulus ( $\mathrm{pH}$ 6.4). This observation is also in concert with the published inhibitory effect of PtdIns $(4,5) \mathrm{P}_{2}$ on TRPV1 (Chuang et al., 2001). The inhibition was reduced but not eliminated by the deletion of the C-terminal 777-820 region (Fig. 8 B) that was implicated by Chuang et al. $(2001)$ in the inhibition by $\operatorname{PtdIns}(4,5) \mathrm{P}_{2}$.

When we used capsaicin as a stimulus, coexpression of PIP5K inhibited the currents at $100 \mathrm{~nm}$ capsaicin (Fig. 8C). At $1 \mu \mathrm{M}$ capsaicin, there was a moderate inhibition by PIP5K, and no inhibition was observed at $10 \mu \mathrm{M}$ capsaicin. The lack of inhibition at $10 \mu \mathrm{M}$ capsaicin shows that the effect of PIP5K is unlikely to be mediated by reduced surface expression. The TRPV $1_{\Delta 777-820} \mathrm{mu}$ tant was not inhibited significantly by PIP5K at $100 \mathrm{nM}$ and $1 \mu \mathrm{M}$ capsaicin. This mutant, however, has a higher sensitivity to capsaicin (Prescott and Julius, 2003). When we tested the effect of PIP5K at 10 nM capsaicin, which corresponds roughly to the relative effect of $100 \mathrm{nM}$ capsaicin on the wild-type TRPV1, we saw an inhibition that was less than that observed on the wild type (Fig. $8 D$ ).

\section{Capsaicin changes the apparent affinity of the activating $\operatorname{PtdIns}(4,5) \mathrm{P}_{2}$ effect}

Menthol, the specific activator of TRPM8, sensitizes that channel to activation by $\operatorname{PtdIns}(4,5) \mathrm{P}_{2}$ [i.e., shifts the $\operatorname{PtdIns}(4,5) \mathrm{P}_{2}$ dose response to the left] (Rohacs et al., 2005). To test the effect of the stimulation strength on the apparent affinity of the activating effect of PtdIns $(4,5) \mathrm{P}_{2}$ on TRPV1, we performed dose-response measurements with $\mathrm{diC}_{8} \operatorname{PtdIns}(4,5) \mathrm{P}_{2}$ in the presence of different capsaicin concentrations (Fig. 9). The $\mathrm{EC}_{50}$ for $\operatorname{PtdIns}(4,5) \mathrm{P}_{2}$ at $+100 \mathrm{mV}$ was $4.9 \pm 2.7,20.3 \pm 2.5$, and $309.7+54.6 \mu \mathrm{M}$ in the presence of 10,1 , and $0.5 \mu \mathrm{M}$ capsaicin, respectively. The Hill coefficients were $0.69 \pm 0.09,0.88 \pm 0.06$, and $1.25 \pm 0.22$ in the presence of 10,1 , and $0.5 \mu \mathrm{M}$ capsaicin, respectively. Note that in the presence of $0.5 \mu \mathrm{M}$ capsaicin, $\operatorname{diC}_{8} \operatorname{PtdIns}(4,5) \mathrm{P}_{2}$ elicited very small responses that showed no signs of saturation at higher PtdIns $(4,5) \mathrm{P}_{2}$ concentrations; therefore, we were unable to fit the data with a Hill function. In each of those experiments, we applied a pulse of $50 \mu \mathrm{M} \mathrm{diC}{ }_{8} \operatorname{PtdIns}(4,5) \mathrm{P}_{2}$ together with $10 \mu \mathrm{M}$ capsaicin and calculated the expected maximum response from that value. Using the calculated $I_{\max }$, we could fit the points with a Hill function. It is not possible to tell from the data whether in the presence of $0.5 \mu \mathrm{M}$ capsaicin the $I_{\max }$ evoked by $\operatorname{PtdIns}(4,5) \mathrm{P}_{2}$ is the same or different from that in the presence of $10 \mu \mathrm{M}$ capsaicin; therefore, the given values for the $\mathrm{EC}_{50}$ and Hill coefficient 


\section{A Pt-ase domain}
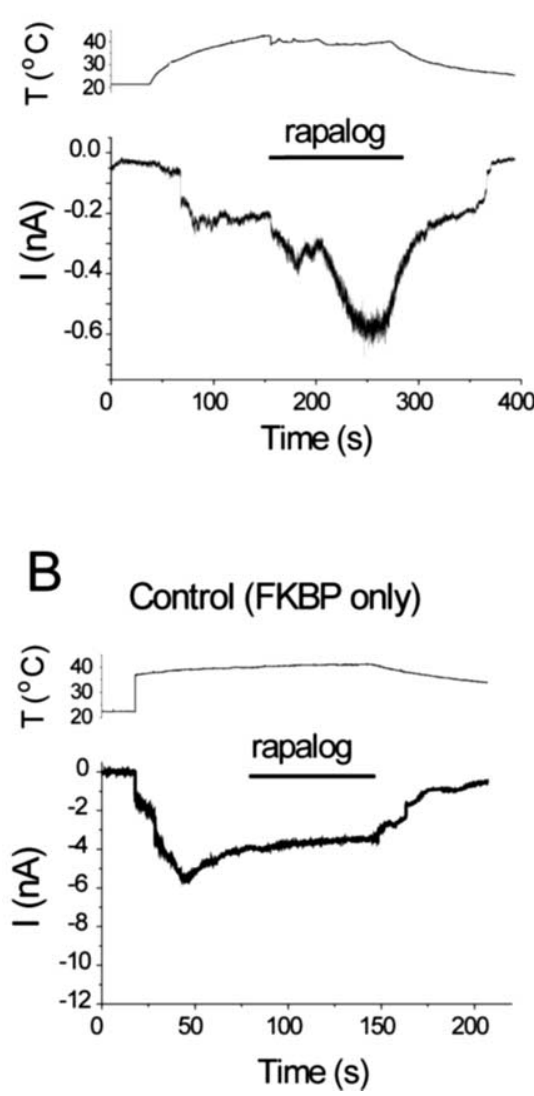
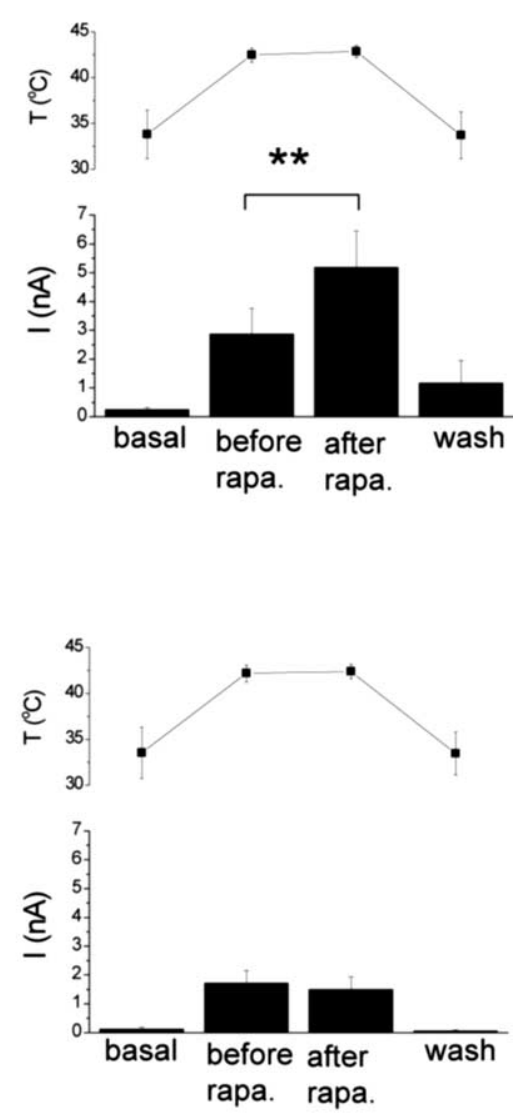

Figure 7. Conversion of $\mathrm{Ptd} \operatorname{lns}(4,5) \mathrm{P}_{2}$ to $\mathrm{Ptdln}$ (4)P increases currents stimulated by moderately high temperatures. HEK cells were transfected with TRPV1 and the CFP-tagged FRB (T2098L) and either the RFP-tagged FKBP12 (control) or the FKBP12 fused to the phosphatase domain of the PIP 2 5-phosphatase (Pt-ase domain). Measurements were performed at $-60 \mathrm{mV}$ in the whole-cell configuration. $\boldsymbol{A}$, The effect of rapalog in the FKBP-phosphatase domain-expressing cells. Left, Representative trace for currents (l; bottom) and temperature (T; top) recorded in the same experiment. The horizontal bar shows the application of 500 nм rapalog. Right, Summary of the data $(n=9)$. Current and temperature values were measured just before the current started increasing (basal), before the application of rapalog (before rapa.), $20-30 \mathrm{~s}$ after the application of rapalog (after rapa.), and at the end of the decreasing phase of the temperature protocol after the washout of rapalog (wash). $\boldsymbol{B}$, Similar experiments in control cells $(n=9)$.

should only be treated as approximation in the presence of $0.5 \mu \mathrm{M}$ capsaicin. Nevertheless, it is clear from the data that the $\mathrm{EC}_{50}$ for PtdIns $(4,5) \mathrm{P}_{2}$ is shifted to the right at lower capsaicin concentrations.

Rundown of current activity in ATP-free excised patches is thought to be attributable to dephosphorylation of $\operatorname{PtdIns}(4,5) \mathrm{P}_{2}$ by endogenous lipid phosphatases for many $\operatorname{PtdIns}(4,5) \mathrm{P}_{2^{-}}$ sensitive channels (Hilgemann and Ball, 1996). The velocity of rundown shows correlation with the apparent affinity for PtdIns $(4,5) \mathrm{P}_{2}$; channels with lower PtdIns $(4,5) \mathrm{P}_{2}$ affinity run down faster (Zhang et al., 1999). In the presence of $0.5 \mu \mathrm{M}$ capsaicin, current activity ran down faster than in the presence of 1 or $10 \mu \mathrm{M}$ capsaicin (Fig. 9D). This is again consistent with the lower apparent affinity of TRPV1 for $\operatorname{PtdIns}(4,5) \mathrm{P}_{2}$ in the presence of low capsaicin concentrations.

\section{Discussion}

\section{The role of phosphoinositides in the desensitization} of TRPV1

High capsaicin concentrations in the presence of extracellular $\mathrm{Ca}^{2+}$ lead to transient activation of TRPV1 currents, a phenomenon called desensitization. Here, we show that $\operatorname{PtdIns}(4,5) \mathrm{P}_{2}$,
PtdIns(4)P, and other phosphoinositides activate TRPV1 in excised patches. We also demonstrate that activation of TRPV1 in the presence of extracellular $\mathrm{Ca}^{2+}$ leads to the activation of PLC and the depletion of PtdIns (4,5) $\mathrm{P}_{2}$ and PtdIns(4)P. The PLC inhibitor U73122 and inclusion of PtdIns $(4,5) \mathrm{P}_{2}$ or PtdIns(4)P in the patch pipette during whole-cell measurements inhibited desensitization. The likely interpretation of our data is that after activation of PLC, the ensuing phosphoinositide depletion removes $\operatorname{PtdIns}(4,5) \mathrm{P}_{2}$ and PtdIns(4)P from their activating site(s), leading to desensitization of TRPV1 currents.

Locally applied capsaicin is widely used as an analgesic. The rationale behind this is that after an initial phase, when it elicits an intense burning sensation, capsaicin receptors become desensitized, and this provides pain relief (Szallasi and Blumberg, 1999). The initial burning sensation, however, can be very intense, especially when capsaicin is used in higher concentrations, which leads to low patient compliance (Sawynok, 2003). The involvement of phosphoinositide depletion in the desensitization of TRPV1 raises the interesting possibility that altering $\operatorname{PtdIns}(4,5) \mathrm{P}_{2}$ metabolism locally may allow better local pain control, with less side effects.

\section{The effect of PtdIns(4)P}

PtdIns(4)P, the precursor of PtdIns $(4,5) \mathrm{P}_{2}$, activated TRPV1 in excised patches (Fig. $1 B, C$ ) and inhibited desensitization similarly to $\operatorname{PtdIns}(4,5) \mathrm{P}_{2}$ (Fig. $4 E, J)$. In the plasma membrane, PtdIns(4)P is found in quantities comparable to that of PtdIns $(4,5) \mathrm{P}_{2}$ (Fruman et al., 1998), thus it is likely that PtdIns(4)P plays a role in keeping TRPV1 open in a cellular context. Consistent with this, conversion of PtdIns $(4,5) \mathrm{P}_{2}$ to PtdIns(4)P did not inhibit TRPV1 currents at saturating capsaicin concentrations (Fig. 6A). Although PtdIns $(4,5) \mathrm{P}_{2}$ has received a lot of attention recently (Hilgemann et al., 2001; Suh and Hille, 2005), much less is known about the role of PtdIns(4)P as a regulator of ion channels. It was shown that PtdIns(4)P activates some members of the inwardly rectifying $\mathrm{K}^{+}$channel family in excised patches (Fan and Makielski, 1997; Baukrowitz et al., 1998; Rohacs et al., 1999), but its role in the regulation of these channels in a cellular context is not established. PtdIns(4)P also activates TRPM4 (Z. Zhang et al., 2005; Nilius et al., 2006) and TRPM8 (Rohacs et al., 2005), but its effect is much smaller than that of $\operatorname{PtdIns}(4,5) \mathrm{P}_{2}$. Our data suggest that PtdIns(4)P plays an important role in maintaining the activity of TRPV1, which, as we discuss below, is distinct from that of PtdIns $(4,5) \mathrm{P}_{2}$ in certain aspects.

The inhibitory effect of $\operatorname{PtdIns}(4,5) \mathrm{P}_{2}$ We found that PtdIns $(4,5) \mathrm{P}_{2}$ partially inhibits TRPV1 in intact cells, an effect that is only prevalent at low stimulation strength. This is based on the following findings. Depletion of 
PtdIns $(4,5) \mathrm{P}_{2}$ with a rapamycin-inducible $\mathrm{PIP}_{2}$ 5-phosphatase potentiated TRPV1 currents at low capsaicin concentration (Fig. 6B and supplemental Fig. 4, available at www.jneurosci.org as supplemental material) and when activated by moderate heating (Fig. 7). Increasing PtdIns $(4,5) \mathrm{P}_{2}$ levels by coexpressing PIP5K inhibited TRPV1 currents that were evoked by low capsaicin concentrations or a moderate drop in $\mathrm{pH}$ (Fig. 8.). These data are consistent with the previous report (Chuang et al., 2001) suggesting an inhibitory effect of PtdIns $(4,5) \mathrm{P}_{2}$, especially considering that PLC-mediated potentiation is also mainly prevalent at low stimulus strength. Our data also suggest that the inhibitory effect is specific for $\operatorname{PtdIns}(4,5) \mathrm{P}_{2}$ over PtdIns(4)P, raising the interesting possibility that specific changes in levels of PtdIns( 4,5$) \mathrm{P}_{2}$ or PtdIns(4)P by lipid kinases and phosphatases may have distinct effects on ion channels. It is likely that the inhibitory effect of PtdIns $(4,5) \mathrm{P}_{2}$ is indirect, because we and others (Stein et al., 2006) could not detect it in excised patches. It is possible, for example, that it is mediated by a cytoplasmic PtdIns $(4,5) \mathrm{P}_{2}$ binding protein or some other factor that is quickly lost in excised patches. It will require additional studies to identify the additional factor(s) that is required for the inhibitory effect of $\operatorname{PtdIns}(4,5) \mathrm{P}_{2}$.

The inhibitory effect of $\operatorname{PtdIns}(4,5) \mathrm{P}_{2}$ on TRPV1 was proposed to play a role in sensitization of TRPV1 to moderate stimuli by PLC-coupled agonists such as bradykinin and NGF (Chuang et al., 2001). Various other mechanisms have also been proposed to underlie this phenomenon. For bradykinin (Premkumar et al., 2005), extracellular ATP (Tominaga et al., 2001), and CCL3 (N. Zhang et al., 2005), the involvement of protein kinase $\mathrm{C}$ (PKC) was also demonstrated. It was shown that NGF induces translocation of TRPV1 to the plasma membrane, thus increasing the number of active channels (X. Zhang et al., 2005). This finding was later confirmed, and it was also demonstrated that NGF treatment increases the maximal response to capsaicin, with minimal effect on $\mathrm{EC}_{50}$ (Stein et al., 2006). In contrast, agonists of G-protein-coupled receptors, such as ATP, sensitize mainly by shifting the capsaicin dose response to the left (Tominaga et al., 2001), similarly to PKC (Vellani et al., 2001). It is clear that multiple pathways contribute to sensitization of TRPV1 currents and that various agonists may use different mechanisms (Zhang and McNaughton, 2006). It will require future studies to understand the relative contri-
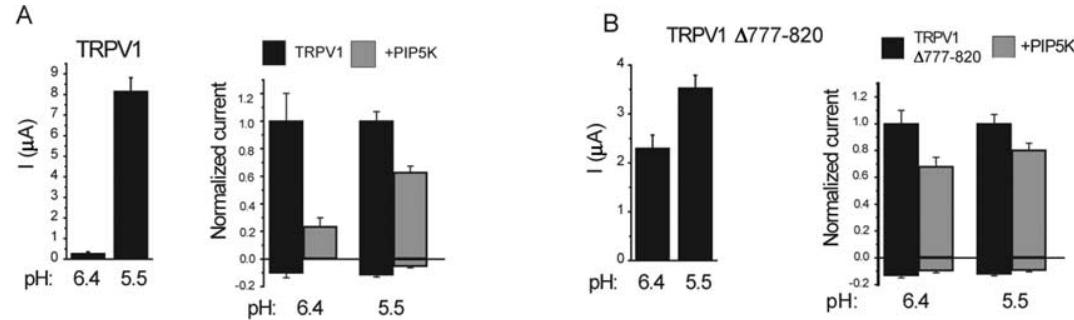

C
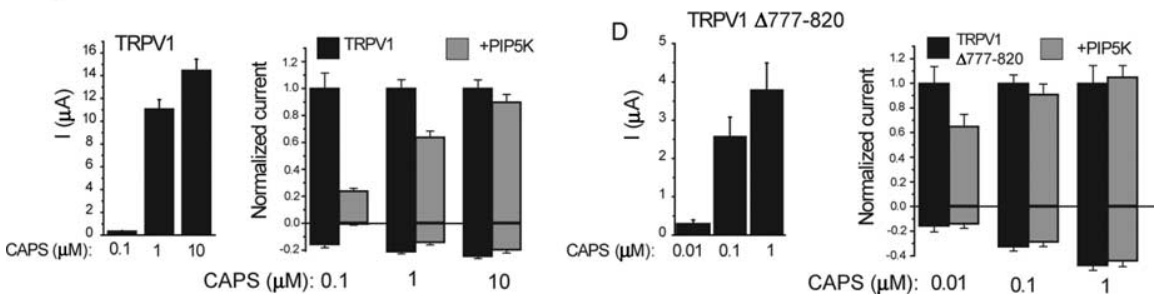

Figure 8. The effect of coexpression of PIP5K on TRPV1 currents in Xenopus 0ocytes. TRPV1 currents were measured with TEVC, as described in Materials and Methods. Currents at +100 and $-100 \mathrm{mV}$ are shown. Left panels show average current amplitudes, and right panels show currents normalized to current amplitudes elicited by the actual stimulus without PIP5K coexpression. $\boldsymbol{A}, \boldsymbol{B}$, The effect of PIP5K on low pH (6.5 and 5.5)-induced currents is shown for the wild type $(\boldsymbol{A})$ and the $\Delta 777-820$ mutant $(\boldsymbol{B})$ of TRPV1. C, $\boldsymbol{D}$, The effect of PIP5K on capsaicin (CAPS)-induced currents is shown for the wild type (C) and the $\Delta 777-820$ mutant (D) of TRPV1.
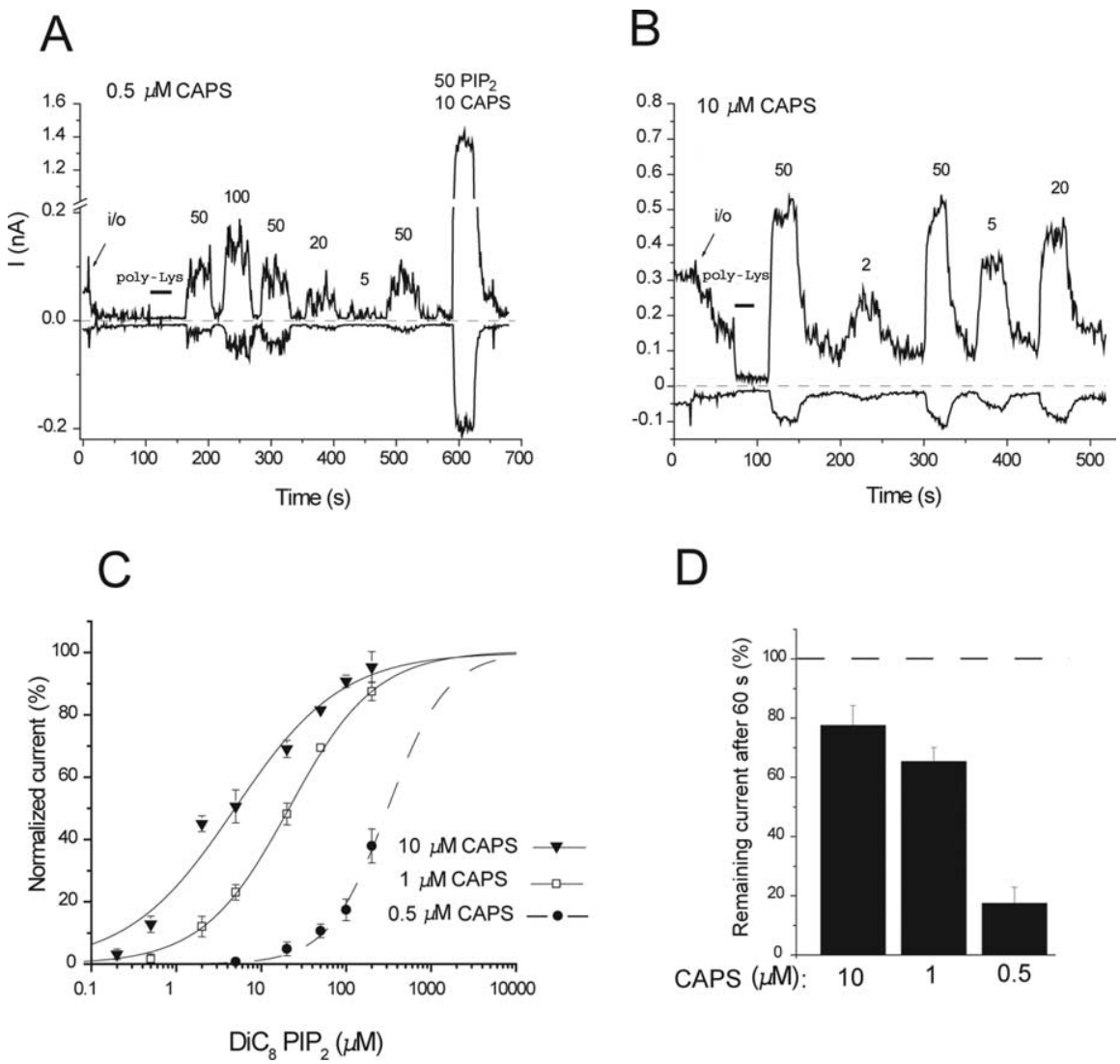

D

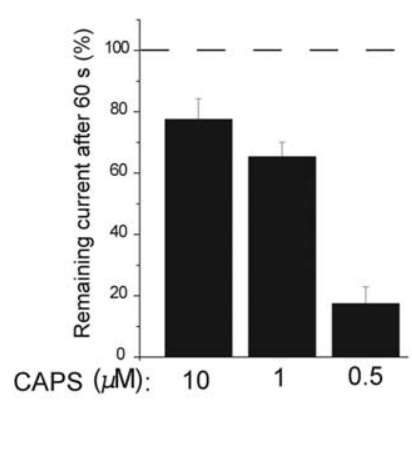

Figure 9. High capsaicin (CAPS) concentrations increase the apparent affinity of TRPV1 for Ptdlns $(4,5) P_{2}$. $\boldsymbol{A}, \boldsymbol{B}$, Representative traces in the presence of $0.5 \mu \mathrm{m}$ capsaicin $(\boldsymbol{A})$ and $10 \mu \mathrm{m}$ capsaicin $(\boldsymbol{B})$ for dose responses with $\mathrm{diC}_{8}$ Ptdlns $(4,5) \mathrm{P}_{2}$. $\boldsymbol{C}$, Hill fits of the $\operatorname{Ptdlns}(4,5) P_{2}$ dose responses at various capsaicin concentrations $(+100 \mathrm{mV}) . \boldsymbol{D}$, Statistics of the current rundown in the presence of various capsaicin concentrations ( $n=8,44$, and 11 for 10,1 , and $0.5 \mu \mathrm{m}$ capsaicin, respectively). In the presence of 1 and $10 \mu \mathrm{m}$ capsaicin, there was an immediate change in current after excision, which was quite variable: sometimes an increase, sometimes a decrease or no change; therefore, the values given are normalized to the current immediately after excision. In the presence of $0.5 \mu \mathrm{m}$ capsaicin in many patches, there was a fast increase, but it disappeared so rapidly that its amplitude was not always possible to determine; thus, the values were normalized to the cell-attached level. 
butions of PtdIns $(4,5) \mathrm{P}_{2}$ depletion and other pathways to sensitization of TRPV1.

\section{How to reconcile the opposing effects of $\operatorname{PtdIns}(4,5) \mathrm{P}_{2}$ on TRPV1?}

In the presence of saturating capsaicin concentrations, $\operatorname{PtdIns}(4,5) \mathrm{P}_{2}$ and/or PtdIns(4)P are needed for channel activity, and no inhibitory effect is present. In the presence of moderate stimuli, such as low capsaicin concentrations or moderate increases of temperature, the situation is more complicated, because both inhibition and activation are present. A concurrent presence of an activating and inhibitory effect is likely to result in a bell-shaped dependence of channel activity on $\operatorname{PtdIns}(4,5) \mathrm{P}_{2}$ levels. If resting PtdIns $(4,5) \mathrm{P}_{2}$ levels are to the right of the peak of such a bell-shaped dose response, a moderate $\operatorname{PtdIns}(4,5) \mathrm{P}_{2}$ depletion would result in channel activation, whereas increased $\operatorname{PtdIns}(4,5) \mathrm{P}_{2}$ levels would result in channel inhibition, which is consistent with our data. Similar opposing effects of PtdIns $(4,5) \mathrm{P}_{2}$ were shown for voltage-dependent $\mathrm{Ca}^{2+}$ channels (Wu et al., 2002), thus dual regulation by phosphoinositides may be a general phenomenon among ion channels.

Our model implies that during the phenomenon of sensitization, PLC-coupled agonists induce a moderate depletion of $\operatorname{PtdIns}(4,5) \mathrm{P}_{2}$, removing the inhibitory effect of $\operatorname{PtdIns}(4,5) \mathrm{P}_{2}$ but not reaching low enough lipid levels to inhibit channel activity. In contrast, we assume that high capsaicin concentrations induce a severe depletion of $\operatorname{PtdIns}(4,5) \mathrm{P}_{2}$ that limits channel activity during desensitization. When discussing severe and moderate $\operatorname{PtdIns}(4,5) \mathrm{P}_{2}$ depletion, we have to keep in mind that it is the local phosphoinositide concentration that determines channel activity, which is difficult to measure. It is also possible that the inhibitory and activating $\operatorname{PtdIns}(4,5) \mathrm{P}_{2}$ molecules are in different pools. PLC-coupled agonists mainly activate PLC $\beta$ and PLC $\gamma$ isoforms, as opposed to capsaicin, which is likely to activate PLC $\delta$ isoforms. The different PLC isoforms may have different access to the PtdIns $(4,5) \mathrm{P}_{2}$ molecule that exerts the inhibitory effect and the one that exerts the activating effect. Finally, it is also possible that different PLC isoforms deplete PtdIns(4)P versus PtdIns $(4,5) \mathrm{P}_{2}$ to different extents, which may also contribute to differential effects on the channel.

Our study mainly focused on capsaicin, but it is likely that phosphoinositides exert dual effects on TRPV1 currents activated by protons and heat also. PLC-coupled agonists do not only sensitize TRPV1 to capsaicin but also to protons and heat (Chuang et al., 2001). We have shown that $\mathrm{H}^{+}$-induced currents were inhibited by PIP5K and that currents evoked by moderate heating were potentiated by rapalog-induced $\operatorname{PtdIns}(4,5) \mathrm{P}_{2}$ depletion. TRPV1 currents also desensitize when activated by a large drop in $\mathrm{pH}$ (Bhave et al., 2002). Although the role of phosphoinositides in the desensitization of TRPV1 induced by protons is feasible, it needs to be addressed experimentally in the future. TRPV1 is also activated by depolarization; both heat and capsaicin induce large shifts in the voltage dependence of TRPV1, and lower capsaicin concentrations induce smaller shifts in voltage dependence than higher capsaicin concentrations (Voets et al., 2004). Several of our measurements were performed at various voltages, and generally the effects of manipulating phosphoinositide levels were similar at positive and negative voltages (Figs. 1, 8, 9 and supplemental Fig. 4, available at www.jneurosci.org as supplemental material). Thus, it is unlikely that the differential effects of phosphoinositides are attributable to the different voltage shifts at low and high capsaicin concentrations. The dose-response relationships of both PtdIns(4,5) $\mathrm{P}_{2}$ and PtdIns(4)P were slightly left- shifted at positive voltages (Fig. 1C), therefore voltage also modulates the effect of phosphoinositides on TRPV1, similarly to TRPM8 (Rohacs et al., 2005).

\section{Summary}

Our data show that phosphoinositides have dual effects on TRPV1 and the balance between the inhibitory and activating effects depend on the strength of stimulation. The activating effect of phosphoinositides is likely to be direct, because it prevails in excised patches. We show that activation of TRPV1 by high capsaicin concentrations in the presence of extracellular $\mathrm{Ca}^{2+}$ leads to activation of PLC and the ensuing depletion of $\operatorname{PtdIns}(4,5) \mathrm{P}_{2}$ and PtdIns(4)P contributes to the desensitization of these channels. Our data also demonstrate the existence of an inhibitory effect of PtdIns $(4,5) \mathrm{P}_{2}$ on TRPV1 at low stimulation levels in intact cells. Obviously, the regulation of TRPV1 by phosphoinositides is highly complex. Additional studies are required to fully elucidate the mechanism and the interplay between the activating and inhibitory phosphoinositide effects.

\section{References}

Balla A, Tuymetova G, Tsiomenko A, Varnai P, Balla T (2005) A plasma membrane pool of phosphatidylinositol 4-phosphate is generated by phosphatidylinositol 4-kinase type-III alpha: studies with the $\mathrm{PH}$ domains of the oxysterol binding protein and FAPP1. Mol Biol Cell 16:1282-1295.

Balla T (2001) Pharmacology of phosphoinositides, regulators of multiple cellular functions. Curr Pharm Des 7:475-507.

Baukrowitz T, Schulte U, Oliver D, Herlitze S, Krauter T, Tucker SJ, Ruppersberg JP, Fakler B (1998) PIP $_{2}$ and PIP as determinants for ATP inhibition of KATP channels. Science 1141-1144.

Bhave G, Zhu W, Wang H, Brasier DJ, Oxford GS, Gereau RW (2002) cAMP-dependent protein kinase regulates desensitization of the capsaicin receptor (VR1) by direct phosphorylation. Neuron 35:721-731.

Caterina MJ, Julius D (2001) The vanilloid receptor: a molecular gateway to the pain pathway. Annu Rev Neurosci 24:487-517.

Caterina MJ, Schumacher MA, Tominaga M, Rosen TA, Levine JD, Julius D (1997) The capsaicin receptor: a heat-activated ion channel in the pain pathway. Nature 389:816-824

Chuang HH, Prescott ED, Kong H, Shields S, Jordt SE, Basbaum AI, Chao MV, Julius D (2001) Bradykinin and nerve growth factor release the capsaicin receptor from $\operatorname{PtdIns}(4,5) \mathrm{P}_{2}$ mediated inhibition. Nature 411:957-962.

Docherty RJ, Yeats JC, Bevan S, Boddeke HW (1996) Inhibition of calcineurin inhibits the desensitization of capsaicin-evoked currents in cultured dorsal root ganglion neurones from adult rats. Pflügers Arch 431:828-837.

Fan Z, Makielski JC (1997) Anionic phospholipids activate ATP-sensitive potassium channels. J Biol Chem 272:5388-5395.

Fruman DA, Meyers RE, Cantley LC (1998) Phosphoinositide kinases. Annu Rev Biochem 67:481-507.

Hardie RC (2007) TRP channels and lipids: from Drosophila to mammalian physiology. J Physiol (Lond) 578:9-24.

Hilgemann DW, Ball R (1996) Regulation of cardiac $\mathrm{Na}^{+} / \mathrm{Ca}^{2+}$ exchange and $\mathrm{K}_{\mathrm{ATP}}$ potassium channels by $\mathrm{PIP}_{2}$. Science 273:956-959.

Hilgemann DW, Feng S, Nasuhoglu C (2001) The complex and intriguing lives of $\mathrm{PIP}_{2}$ with ion channels and transporters. Sci STKE 2001:RE19.

Hirose K, Kadowaki S, Tanabe M, Takeshima H, Iino M (1999) Spatiotemporal dynamics of inositol 1,4,5-trisphosphate that underlies complex $\mathrm{Ca}^{2+}$ mobilization patterns. Science 284:1527-1530.

Horowitz LF, Hirdes W, Suh BC, Hilgemann DW, Mackie K, Hille B (2005) Phospholipase $\mathrm{C}$ in living cells: activation, inhibition, $\mathrm{Ca}^{2+}$ requirement, and regulation of M current. J Gen Physiol 126:243-262.

Koplas PA, Rosenberg RL, Oxford GS (1997) The role of calcium in the desensitization of capsaicin responses in rat dorsal root ganglion neurons. J Neurosci 17:3525-3537.

Lin CW, Yan F, Shimamura S, Barg S, Shyng SL (2005) Membrane phosphoinositides control insulin secretion through their effects on ATPsensitive $\mathrm{K}^{+}$channel activity. Diabetes 54:2852-2858. 
Liu B, Zhang C, Qin F (2005) Functional recovery from desensitization of vanilloid receptor TRPV1 requires resynthesis of phosphatidylinositol 4,5-bisphosphate. J Neurosci 25:4835-4843.

Mohapatra DP, Nau C (2003) Desensitization of capsaicin-activated currents in the vanilloid receptor TRPV1 is decreased by the cyclic AMPdependent protein kinase pathway. J Biol Chem 278:50080-50090.

Mohapatra DP, Nau C (2005) Regulation of $\mathrm{Ca}^{2+}$-dependent desensitization in the vanilloid receptor TRPV1 by calcineurin and cAMPdependent protein kinase. J Biol Chem 280:13424-13432.

Moriyama T, Iida T, Kobayashi K, Higashi T, Fukuoka T, Tsumura H, Leon C, Suzuki N, Inoue K, Gachet C, Noguchi K, Tominaga M (2003) Possible involvement of P2Y2 metabotropic receptors in ATP-induced transient receptor potential vanilloid receptor 1-mediated thermal hypersensitivity. J Neurosci 23:6058-6062.

Nakanishi S, Catt KJ, Balla T (1995) A wortmannin-sensitive phosphatidylinositol 4-kinase that regulates hormone-sensitive pools of inositol phospholipids. Proc Natl Acad Sci USA 92:5317-5321.

Nilius B, Mahieu F, Prenen J, Janssens A, Owsianik G, Vennekens R, Voets T (2006) The $\mathrm{Ca}^{2+}$-activated cation channel TRPM4 is regulated by phosphatidylinositol 4,5-biphosphate. EMBO J 25:467-478.

Premkumar LS, Raisinghani M, Pingle SC, Long C, Pimentel F (2005) Downregulation of transient receptor potential melastatin 8 by protein kinase C-mediated dephosphorylation. J Neurosci 25:11322-11329.

Prescott ED, Julius D (2003) A modular PIP $_{2}$ binding site as a determinant of capsaicin receptor sensitivity. Science 300:1284-1288.

Rebecchi MJ, Pentyala SN (2000) Structure, function, and control of phosphoinositide-specific phospholipase C. Physiol Rev 80:1291-1335.

Rohacs T (2007) Regulation of TRP channels by $\mathrm{PIP}_{2}$. Pflügers Arch 453:753-762.

Rohacs T, Nilius B (2007) Regulation of transient receptor potential (TRP) channels by phosphoinositides. Pflügers Arch, in press.

Rohacs T, Chen J, Prestwich GD, Logothetis DE (1999) Distinct specificities of inwardly rectifying $\mathrm{K}^{+}$channels for phosphoinositides. J Biol Chem 274:36065-36072.

Rohacs T, Lopes CMB, Michailidis I, Logothetis DE (2005) PI $(4,5)_{2}$ regulates the activation and desensitization of TRPM8 channels through the TRP domain. Nat Neurosci 8:626-634.

Roy A, Levine TP (2004) Multiple pools of phosphatidylinositol 4-phosphate detected using the pleckstrin homology domain of Osh2p. J Biol Chem 279:44683-44689.

Sawynok J (2003) Topical and peripherally acting analgesics. Pharmacol Rev 55:1-20.

Shyng SL, Barbieri A, Gumusboga A, Cukras C, Pike L, Davis JN, Stahl PD, Nichols CG (2000) Modulation of nucleotide sensitivity of ATPsensitive potassium channels by phosphatidylinositol-4-phosphate 5-kinase. Proc Natl Acad Sci USA 97:937-941.

Stein AT, Ufret-Vincenty CA, Hua L, Santana LF, Gordon SE (2006) Phosphoinositide 3-kinase binds to TRPV1 and mediates NGF-stimulated TRPV1 trafficking to the plasma membrane. J Gen Physiol 128:509-522.
Suh BC, Hille B (2005) Regulation of ion channels by phosphatidylinositol 4,5-bisphosphate. Curr Opin Neurobiol 15:370-378.

Suh BC, Inoue T, Meyer T, Hille B (2006) Rapid chemically induced changes of PtdIns $(4,5) \mathrm{P}_{2}$ gate KCNQ ion channels. Science 314:1454-1457.

Szallasi A, Blumberg PM (1999) Vanilloid (Capsaicin) receptors and mechanisms. Pharmacol Rev 51:159-212.

Tominaga M, Caterina MJ, Malmberg AB, Rosen TA, Gilbert H, Skinner K, Raumann BE, Basbaum AI, Julius D (1998) The cloned capsaicin receptor integrates multiple pain-producing stimuli. Neuron 21:531-543.

Tominaga M, Wada M, Masu M (2001) Potentiation of capsaicin receptor activity by metabotropic ATP receptors as a possible mechanism for ATPevoked pain and hyperalgesia. Proc Natl Acad Sci USA 98:6951-6956.

van der Wal J, Habets R, Varnai P, Balla T, Jalink K (2001) Monitoring agonist-induced phospholipase $\mathrm{C}$ activation in live cells by fluorescence resonance energy transfer. J Biol Chem 276:15337-15344.

Varnai P, Balla T (1998) Visualization of phosphoinositides that bind pleckstrin homology domains: calcium- and agonist-induced dynamic changes and relationship to myo- ${ }^{3} \mathrm{Hinositol-labeled} \mathrm{phosphoinositide} \mathrm{pools.}$ J Cell Biol 143:501-510.

Varnai P, Thyagarajan B, Rohacs T, Balla T (2006) Rapidly inducible changes in phosphatidylinositol 4,5-bisphosphate levels influence multiple regulatory functions of the lipid in intact cells. J Cell Biol 175:377-382.

Vellani V, Mapplebeck S, Moriondo A, Davis JB, McNaughton PA (2001) Protein kinase $\mathrm{C}$ activation potentiates gating of the vanilloid receptor VR1 by capsaicin, protons, heat and anandamide. J Physiol (Lond) 534:813-825.

Voets T, Nilius B (2007) Modulation of TRPs by PIPs. J Physiol (Lond), in press.

Voets T, Droogmans G, Wissenbach U, Janssens A, Flockerzi V, Nilius B (2004) The principle of temperature-dependent gating in cold- and heatsensitive TRP channels. Nature 430:748-754.

Wu L, Bauer CS, Zhen XG, Xie C, Yang J (2002) Dual regulation of voltagegated calcium channels by PtdIns $(4,5) \mathrm{P}_{2}$. Nature 419:947-952.

Zhang H, He C, Yan X, Mirshahi T, Logothetis DE (1999) Activation of inwardly rectifying $\mathrm{K}^{+}$channels by distinct PtdIns $(4,5) \mathrm{P}_{2}$ interactions. Nat Cell Biol 1:183-188.

Zhang N, Inan S, Cowan A, Sun R, Wang JM, Rogers TJ, Caterina M, Oppenheim JJ (2005) A proinflammatory chemokine, CCL3, sensitizes the heat- and capsaicin-gated ion channel TRPV1. Proc Natl Acad Sci USA 102:4536-4541.

Zhang X, McNaughton PA (2006) Why pain gets worse: the mechanism of heat hyperalgesia. J Gen Physiol 128:491-493.

Zhang X, Huang J, McNaughton PA (2005) NGF rapidly increases membrane expression of TRPV1 heat-gated ion channels. EMBO J 24:4211-4223.

Zhang Z, Okawa H, Wang Y, Liman ER (2005) Phosphatidylinositol 4,5bisphosphate rescues TRPM4 channels from desensitization. J Biol Chem 280:39185-39192. 